\title{
Assessment of the Effect of Concomitant Use of Sodium Benzoate and Fructose on the Liver Structure and Function in Young Albino Rats
}

\author{
SHIMAA MOHAMMAD YOUSEF, M.D. ${ }^{\mathbf{1}}{ }^{\mathbf{4}}$; HOREYA ERFAN, M.D. ${ }^{\mathbf{2}}$; MOHAMED A. ZAYED; M.D. ${ }^{\mathbf{1}},{ }^{\mathbf{3}}$ and \\ KARIMA EL-SAYED, M.D. ${ }^{4}$
}

The Department of Medical Physiology, Faculty of Medicine, King Abdulaziz University, Rabigh, Saudi Arabia ${ }^{\mathbf{1}}$;

Department of Histology, Faculty of Medicine, Suez Canal University, Ismailia ${ }^{2}$;

Department of Medical Physiology, Faculty of Medicine, Menoufia University ${ }^{3}$ and

Department of Medical Physiology, Faculty of Medicine, Suez Canal University, Ismailia ${ }^{4}$

\begin{abstract}
Background: Sodium benzoate (SB) is incorporated in many food and pharmacological manufacturing as a preservative. Fructose (FR) is used a as substitute for sugar in many food products.
\end{abstract}

Aim of Study: To test the cumulative effect of the combined daily use of SB and FR on rats' liver.

Material and Methods: Twenty-four young male rats were assigned into four groups: 1- Control group; 2- SB group; $15 \mathrm{mg} / \mathrm{kg} /$ day; 3 - FR group; $10 \mathrm{ml}$ of $10 \%$ fructose/day; and 4- Combined SB +FR group. The rats were followed-up for 28 days. At day 28, animals were sacrificed and blood samples were drawn for liver enzymes analysis. The livers of the rats were divided into two parts; a part for freezing for homogenization and hydrogen peroxide analysis and the other for histopathological assessment.

Results: The liver enzymes showed insignificant changes compared to the control group. The $\mathrm{H} 2 \mathrm{O} 2$ was significantly elevated in SB and SB + FR groups. The liver architecture was negatively affected as detected by hematoxylin and Eosin, periodic acid Schiff and proliferating cells antigen stains.

Conclusion: The combined use of SB and FR lead to detrimental effects on the liver function and structure. This in turn warrant cautious use of these substances and raise questions about the safety of using them in a combination on daily basis.

Key Words: Sodium Benzoate - E211-Fructose - Liver $\mathrm{H}_{2} \mathrm{O}_{2}$.

\section{Introduction}

SODIUM benzoate (SB, E211) is a food preservative that is widely used due to its bacteriostatic and fungistatic characteristics. It is incorporated

\footnotetext{
Correspondence to: Dr. Shimaa Mohammad Yousef, E-Mail: smabrahem@kau.edu.sa drshimaay@gmail.com
}

in soft drinks, sauces and pickles to prolong the shelf life. The absorption of SB is rapid in many species including rats, hamsters, dogs, rabbits and humans. Its peak absorption in humans is reached about 1-2 hours post-ingestion. The SB is eliminated rapidly and almost completely and mainly via urinary excretion in different species including rats and humans [1]. SB is considered safe in general by the United States Food and Drug Administration $[2,3]$. Yet, studies have documented adverse effects of its usage on different body systems and functions including memory and learning deficits in children [4], anxiety and motor deficits [5], decrease in the cerebellar cell number and cerebellar volume [6] and DNA damage in liver cells [3].

$\mathrm{SB}$ has been regarded as safe in the allowed doses $(5 \mathrm{mg} / \mathrm{kg}$ body weight $)$. However, some studies reported adverse side effects which may point to the limitation of its use as a preservative [4] The lethal dose LD50 of SB in rats was documented to be $3140 \mathrm{mg} / \mathrm{kg}$ body weight [1]. Although being bound to the allowed doses in the food industry, a study documented that the cumulative daily dose

\footnotetext{
Abbreviations:

ALT : Alanine aminotransferase.

AST : Aspartate aminotransferase.

FR : Fructose

H\&E : Haematoxylin \& Eosin.

HFCS : High Fructose Corn Syrup.

MADI : The Maximal Allowed Daily Intake.

NASH : Non-alcoholic Steatohepatitis.

PAS : Periodic acid-Schiff.

PCNA : Proliferating Cell Nuclear Antigen.

ROS : Reactive Oxygen Species.

SB : Sodium Benzoate.
} 
of SB may exceed the maximal allowed daily intake (MADI) for both children and adults [7] .

Fructose is one of the simple sugars that is found in honey and fruits. Its use is increased in the last century especially in the western diet as a sweetener in beverages and high fructose corn syrup (HFCS) [8]. The daily individual consumption of fructose showed rapid increment in the past years, ranging between $10 \%$ to $15 \%$ of the daily caloric intake [9]. Fructose is accused as a predisposing factor for many diseases such as nonalcoholic steatohepatitis (NASH), cardiovascular diseases, metabolic syndrome and obesity [9] Fructose is being used as a substituent of glucose for diabetic patients. It has been regarded as being safe. Nevertheless, studies have pointed to the adverse effects of its use [10].

Data are available regarding the drawbacks of fructose on the liver. Many researchers documented that fructose differs from glucose in its characteristic ability to enhance both plasma triglycerides and liver fat [11]. On the other hand, there is a controversy in the researches regarding SB toxicity [12].

Up to the best of our knowledge, the effect of the concomitant use of SB with sweeteners encountered in canned foods and soft drinks on a daily basis of ingestion is still not documented. Due to the wide use of both substances concomitantly in food products and due to the high consumption of the beverages and fast foods by the children and young adults, we attempted to investigate the outcome of the concomitant daily use of SB \& fructose on the liver structure and function. We proposed that the cumulative effect of daily use of a dose three times the MADI, even in non-lethal doses, of SB combined with fructose could have a toxic effect on the hepatic structure and function.

\section{Material and Methods}

\section{Animals:}

Young albino rats with ages about $30 \pm 5$ days $(\mathrm{n}=24,105 \pm 10 \mathrm{gm})$ were purchased from National Ophthalmology Center, Giza, Egypt. Rats were housed in a controlled room temperature and normal 12 hours dark/light cycle in the animal house. This study was carried out in the Physiology Department, Faculty of Medicine, Suez Canal University; 20192020. Rats were on a normal chow diet and free access to water. Rats were kept to acclimate for one week before the beginning of the study.

\section{Chemicals:}

SB (Loba Chemei PVT. LTD - extra pure; 99\% purity) solution was freshly prepared solution every day. Fructose (Cat.No.00757- researchlab.in ) solution was freshly prepared every day in a concentration of $10 \%$.

\section{Experimental protocol:}

Animals were assigned randomly into four groups as follows: Normal control group; sodium benzoate only (SB group); Fructose only (FR group); and combined SB and fructose (SB + FR). The prepared solutions were given separately at two separate time points/ day to avoid overfeeding of the animals. SB was given to animals daily, in a dose of $15 \mathrm{mg} / \mathrm{kg}$ [7] at $9 \mathrm{a} . \mathrm{m}$. Ten millimeters of $10 \%$ FR [13] solution was given to each animal regardless of the weight daily at 12 p.m. Both solutions were given via oral gavage using a metal needle by expertise to prevent undue stress or injury to animals. Rats were kept on the specified treatments and followed-up for 28 days. On the sacrifice day, the livers of the animals were cut into two parts; a part for homogenization and freezing for oxidative stress marker $\left(\mathrm{H}_{2} \mathrm{O}_{2}\right)$ and the other for preservation in formalin for histopathological assessment.

\section{Assessment of liver enzymes:}

A sample of 3c.c. of blood was obtained from animals and let to clot and then centrifuged at 1500 rpm for 5 minutes to obtain serum for assessment of Alanine aminotransferase (ALT) and Aspartate aminotransferase (AST). Liver enzyme analyses were done in a specialized laboratory.

\section{Assessment of $\mathrm{H}_{2} \mathrm{O} 2$ :}

Homogenization of the liver tissue according to the instruction of the kit producer was done. $\mathrm{H} 2 \mathrm{O} 2$ Kits were obtained from Biodiagnostic Company for diagnostic and research reagents. Spectrophotometric analyses of the homogenates were done in a specialized laboratory by a clinical pathology specialist.

Histopathological \& immunohistochemical assessment:

The specimens were fixed in $10 \%$ neutral buffered formalin for 24 hours at room temperature $\left(23-28^{\circ} \mathrm{C}\right)$ and were processed to prepare $5 \mathrm{me}$ thick paraffin sections. The obtained sections were stained using Haematoxylin \& Eosin stain (H\&E) for the general architecture of the liver, periodic acid-Schiff reaction (PAS) for the glycogen content in hepatocyte and Labeled streptavidin-biotin horseradish peroxidase technique for the demonstration of proliferating cell nuclear antigen (PCNA) in the 
rat liver; nuclei are stained blue but the nuclear reaction is stained brown. Qualitative and quantitative assessments were done for histological and immunohistochemical changes in the liver. Quantitative analysis using image-based analysis system (Image J).

\section{Data analysis:}

Data were analyzed using IBM SPSS statistical software version 25. Data are expressed as mean \pm standard deviation and ANOVA and Post-hoc LSD test was used to compare means.

\section{Ethical considerations:}

All experimental procedures of animals used for the current research are according to the recommendations of the Ethical Committee of the Faculty of Medicine, Suez Canal University No. 4235-2020.

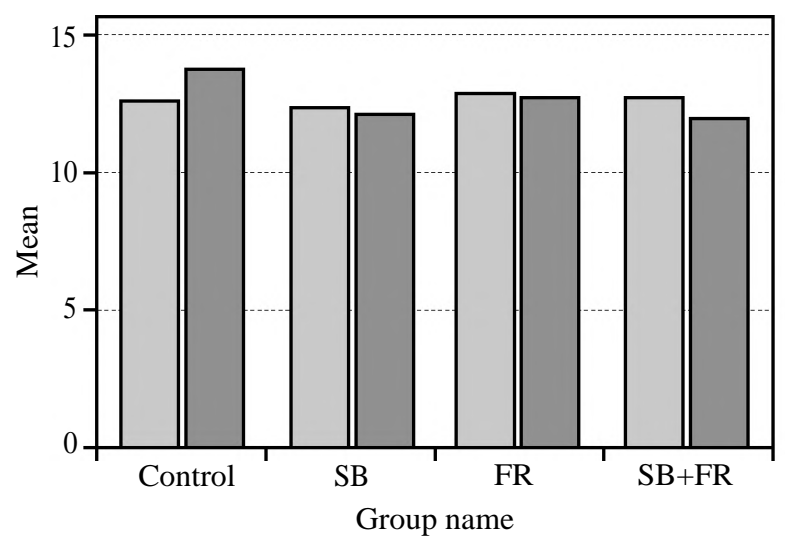

Fig. (1): Demonstrating the mean of ALT \& AST liver enzymes in the study groups.

\section{Results}

\section{Liver enzyme assessment:}

There was no significant difference in the serum AST level in all groups compared to the control group ( $p>0.05$ ). The same was found regarding the ALT level there were insignificant changes in the treated groups compared to the control group ( $p>0.05)$, Fig. (1).

\section{$\mathrm{H}_{2} \mathrm{O} 2$ as oxidative marker:}

The results of the current study revealed a significant difference in the $\mathrm{H}_{2} \mathrm{O} 2$ level in the $\mathrm{SB}$ and $\mathrm{SB}+\mathrm{FR}$ groups compared to the control group $(p<0.05)$. While, there was insignificant changes in the FR group compared to the control group $(p>0.05)$; Fig. (2).

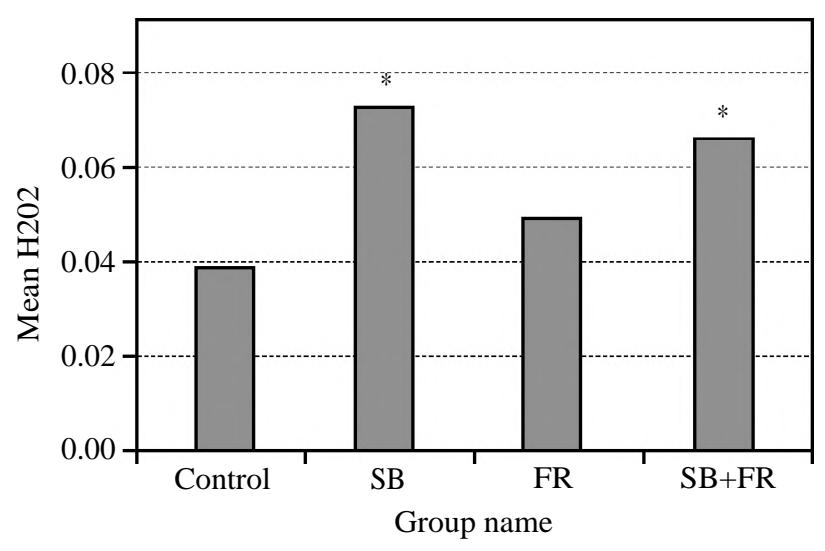

Fig. (2): Demonstrating the $\mathrm{H} 2 \mathrm{O} 2$ level in the study groups.

\section{$\square$ ALT $\quad \square$ AST}

* Significant on comparison to the control group $(p<0.05)$.

\section{Histopathological \& immunohistochemical as-} sessment:

Sections stained by H\&E demonstrated that SB, FR and SB + FR-treated groups revealed marked histopathological changes when compared with the control group. The hepatic architecture was deformed with an abnormal arrangement of hepatocytes, Most of the blood vessels were congested, severe hemorrhage was observed and hepatic necrosis in the form of pyknotic nuclei and others with karyolitic nuclei; Fig. (3) and Table (1).

Sections stained by periodic acid Schiff (PAS) demonstrated the glycogen and showed a strong positive reaction (magenta color) in the cytoplasm of the hepatocytes in the control group. SB, FR and SB + FR-treated groups showed marked glycogen depletion, thus a weak positive reaction in the cytoplasm of hepatocytes when compared with corresponding control animals; Fig. (4) and Table (2).

Examination of the hepatic sections of the controls stained for proliferating cell nuclear antigen (PCNA) antibodies showed a few weak positive nuclear immune reaction indicating the cell divisions of few hepatocytes. However, sections of SB, FR and SB + FR-treated groups displayed strong positive nuclear immune reaction in disrupted hepatocytes to compensate for the lost necrotic hepatocyte; Fig. (5) and Table (3). 

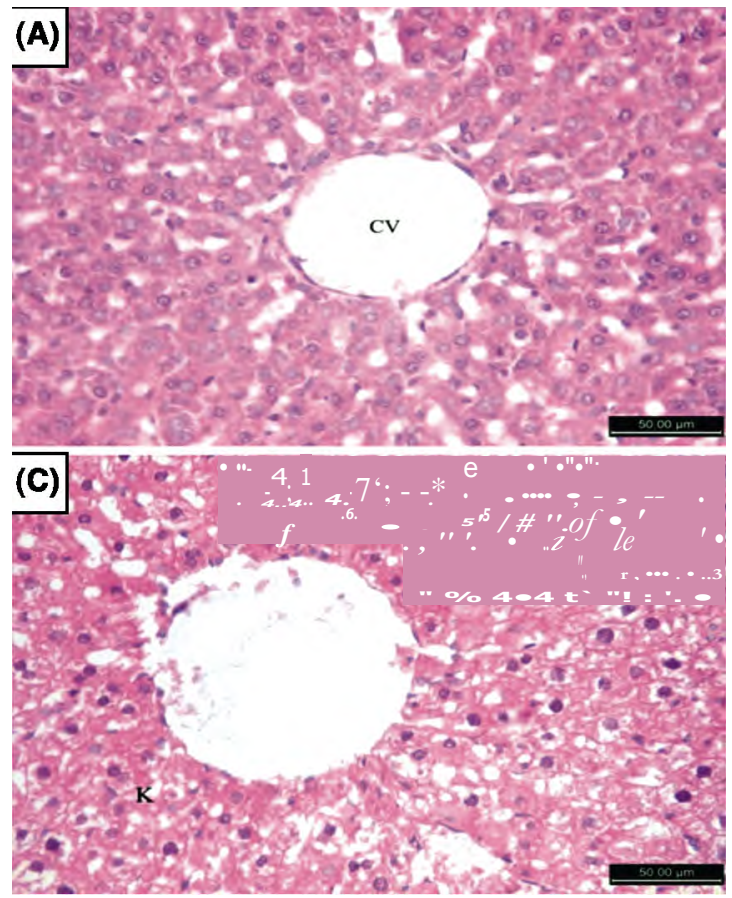
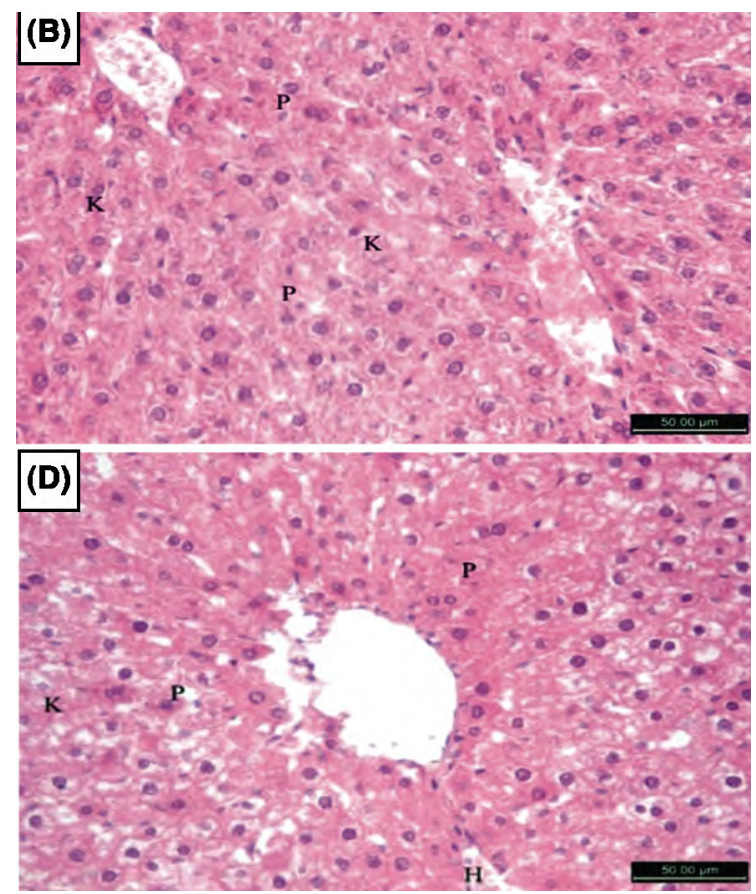

Fig. (3A,B,C\&D): A photomicrograph of a liver section stained with $\mathrm{H} \& \mathrm{E}$.

Fig. (3A): The control rat showing normal hepatic architecture; the hepatocytes and their radiation from the central vein (CV) with eosinophilic cytoplasm and centrally located nuclei. Fig. (3B): A rat administrated with sodium benzoate showing; disorganized hepatic architecture. Some hepatocytes are necrotic with pyknotic nuclei (P) and others with karyolitic nuclei (K). Fig. (3C): A rat administrated with fructose showing; markedly enlarged and vacuolated hepatocytes. It also showed cells devoid of nuclei (karyolitic)[K]. Fig. (3D): A rat administrated with sodium benzoate and fructose showing; that most of the hepatocytes are necrotic with pyknotic nuclei $(\mathrm{P})$ and others with karyolitic nuclei $(\mathrm{K})$. Notice, the hemorrhagic areas $(\mathbf{H})$ among degenerated hepatocytes and hepatocyte disorganization. (H\&E stain, X 400).
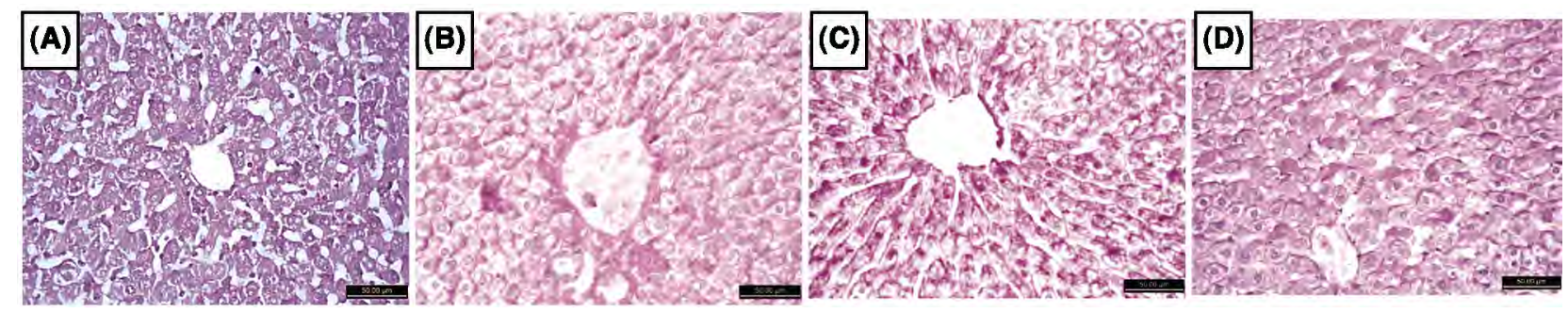

Fig. (4A,B,C\&D): A photomicrograph of a liver section stained with PAS stain.

Fig. (4A): A control rat showing strong PAS positive material in the hepatocyte. Fig. (4B): A rat treated with sodium benzoate showing; decreased intensity of PAS positive material in the hepatocyte. Fig. (4C): A rat administrated with fructose showing; decreased intensity of PAS positive material in the hepatocyte. Fig. (4D): Rats administrated with both sodium benzoate and fructose showing; decreased intensity of PAS positive material in the hepatocyte (PAS stain, X400).

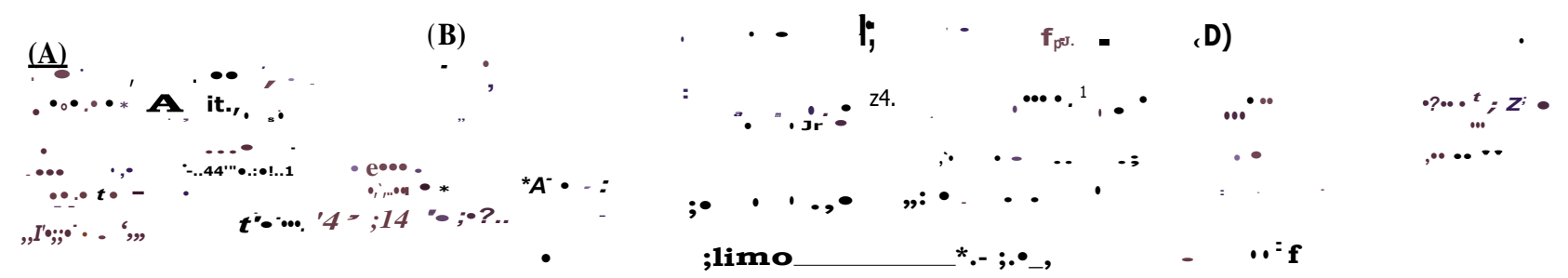

Fig. (5A,B,C\&D): A photomicrograph of a liver section of control rat revealing proliferating cell nuclear antigen (PCNA).

Fig. (5A): PCNA-positive cell staining in the nucleus was brown-yellow and had a fine granular appearance; faint PCNA positive nuclei (?). Notice the negative reaction of other nuclei [A]. Fig. (5B): A rat administrated with sodium benzoate showing; most of the hepatocytes with deep PCNA positive nuclei (f) number of PCNA-immunoreactivity positive cell staining. Fig. (5C): A rat administrated with fructose showing; increased number of PCNA-immunoreactivity positive cell staining. Fig. (5D): A rat administrated with sodium benzoate and fructose showing; increased number of PCNA-immunoreactivity positive cell staining (PCNA stain, X400). 
Table (1): The frequency distribution of the histopathological changes in the liver.

\begin{tabular}{lccc}
\hline \multicolumn{4}{c}{ Histopathological changes } \\
\cline { 2 - 4 } Group & $\begin{array}{c}\text { Ballooning of } \\
\text { hepatocyte \& Vacuolated } \\
\text { eosinophilic cytoplasm (\%) }\end{array}$ & $\begin{array}{c}\text { Nuclear } \\
\text { karyolysis (\%) }\end{array}$ & $\begin{array}{c}\text { Nuclear } \\
\text { pyknosis (\%) }\end{array}$ \\
\hline Control & 0 & 0 & 0 \\
SB & $80 \#$ & $80 \$$ & $50^{*}$ \\
FR & $70 \#$ & $85 \$$ & $55^{*}$ \\
SB + FR & $80 \#$ & $90 \$$ & $60^{*}$ \\
\hline
\end{tabular}

\#, \$, *: Statistically significance compared to control.

Table (2): The mean color-area percentage of PAS reaction.

\begin{tabular}{ll}
\hline Group & Mean \pm SD \\
\hline Control & $48.18 \pm 1.4$ \\
SB & $31.4335 \pm 3.5^{*}$ \\
FR & $41.17 \pm 2.4^{*}$ \\
SB + FR & $43.811 \pm 2.9^{*}$ \\
\hline
\end{tabular}

*Statistically significance compared to control.

Table (3): The mean count of PCNA positive labelled cells in the liver.

\begin{tabular}{ll}
\hline Group & Mean \pm SD \\
\hline Control & $99 \pm 24.2$ \\
SB & $130.9 \pm 15.1^{*}$ \\
FR & $120.7 \pm 31.9^{*}$ \\
SB + FR & $146.7 \pm 16.1^{*}$ \\
\hline
\end{tabular}

*Statistically significance compared to control.

\section{Discussion}

In the current study, we assessed the impact of daily concurrent use of SB and FR. We found that the cumulative daily oral ingestion of these substances leads to hepatotoxicity pronounced by structural damage of the liver and oxidative stress enhancement. However, we did not find significant differences in liver enzymes.

Preservatives are added to food products to inhibit microbial growth or unwanted chemical changes. Benzoate is added to acidic foods and drinks, such as carbonated drinks, vinegar, jams, and fruit juice, as bacteriostatic and fungistatic [7] Fructose has been considered to be safer than glucose [14] . However, studies documented that diets rich in fructose leads to metabolic syndrome, including insulin resistance, obesity, hypertension, and non-alcoholic fatty liver $[15,16]$. In the present work, we used a dose of SB triple the safe dose in an attempt to simulate the cumulative effect of a higher daily dose above the MADI that could be encountered in children and young adults. We did not use a very high dose of fructose to avoid severe injury to the liver by fructose overdose and at the same time get the effect of combining two of the frequently used substances in daily food and pharmacological products.

In the current study, the liver was negatively affected in all the treated groups, however, it was most pronounced in the combined group. The resultant hepatotoxicity was detected via various hepatic stains that pointed to disturbed hepatic architecture, glycogen depletion and the enhanced proliferating cell nuclear antigen (PCNA). The hepatic cell proliferation is a needed process to restore the normal hepatic structure and function. Nevertheless, it has been reported that the enhanced cell proliferation, detected by PCNA, in patients with cirrhotic liver could be an alarming sign for developing hepatocellular carcinoma. While others reported that the decreased proliferation index could also occur in patients with alcoholic inducedhepatitis $[\mathbf{1 7 , 1 8}]$. This can clearly point to the importance of reconsidering the safety of SB as a preservative in the food and pharmacological industry. The same applies for FR as a substitute for glucose for diabetic patients. Khodaei ei al., 2019 have reported similar results to ours. Yet, they found that SB caused renal injury more than hepatic injury. They pointed to the probable hepatic adverse effects on prolonged use of SB as a food preservative [19].

Interestingly, in the current study, there was no significant difference in the serum levels of AST and ALT in the study groups when compared with the control group. This finding may indicate that the histopathological damage either inflicted by the SB or FR per se or combined did not mount to the level that can affect the serum AST and ALT levels. Alternatively, and according to previous reports, liver enzymes levels are usually elevated in acute hepatotoxicity, however, they tend to decrement with prolonged intoxication due to liver damage [20]. In the current study, we induced a sort of sub-chronic rather acute toxicity using a bigger dose.

Our study revealed that SB per se or the combined group induced generation of $\mathrm{H}_{2} \mathrm{O}_{2}$ and this state of augmented oxidative stress probably shared at least in part with liver cell damage. This was in agreement with a previous study that reported that SB induced oxidative stress by increasing Malondialdehyde (MDA) and decreased antioxidative enzymes causing hepatic cellular damage and increased liver enzymes [21]. Additionally, Khoshnoud et al., 2017 showed significant elevation of oxidative activity at different concentrations of Sodium benzoate [4]. On the other hand, we did 
not find a significant effect of fructose only group in contrast to the previous reports. Rats fed high fructose showed hepatic mitochondrial oxidative damage, as well as decreased activity of antioxidant activity. Fructose enhances the imbalance of reactive oxygen species (ROS) via the concomitant overproduction of ROS and suppression of the antioxidant activity, so it causes lipid peroxidation and DNA base damage [22].

The important notice from these previous findings is that the insignificant change in the $\mathrm{H}_{2} \mathrm{O}_{2}$ in the fructose only group points to that the negative effect found in the combined group is mainly induced by SB or that combination could lead to synergetic negative effects on oxidative stress. This in turn raises the attention toward the safety of the SB on prolonged daily use especially because it is involved in many food and pharmacological products. This can lead eventually to exceeding the MADI. What supports our finding is what is documented in a previous study. The researchers calculated the daily intake of SB via eating $250 \mathrm{ml}$ of soup containing less than the maximum admitted inclusion level. They found that this amount represented 44.0-59.7\% of the MADI for children and about 20.3-32.6\% of the MADI for adults. They found nearly the same results on investigating a portion of marinated fish [7]. These findings necessitate reconsidering the usage of SB in food and pharmacological products and taking in consideration the cumulative effects of these products per day and on prolonged exposure.

Collectively, this study shed insight on the harmful effects of the combined daily use of SB in combination with fructose. These harmful effects although not detectable by the ordinary simple liver function enzyme assays, are distinguished by enhancing the oxidative stress at the functional level and by the hepatic damage at the structural level. These data warrant a caution toward the consumption of beverages and fast foods containing SB + FR particularly by the children and young adults, who are the main consumers for these products.

Acknowledgment: We provide thanks to Dr. Ayman Salah Salem, specialist of clinical pathology, Ministry of Health, Egypt; for his rapid and keen response on analyzing tissue homogenate specimens for $\mathrm{H} 2 \mathrm{O} 2$ assay.

\section{Conflict of interest:}

The authors declare no conflict of interest.

\section{Funding:}

This research is funded by the authors.

\section{Author contribution:}

ShY: Generating the idea of the research, methodology formulation and follow-up of laboratory experiments, searching the methods, statistical analysis, editing of the manuscript and discussing the results. HE: Editing \& performing methodology of histopathologic and immune-histochemistry assessment, and performing statistical analysis and commenting on their results. MZ: Statistical analysis, editing of the manuscript and discussing the results. KEl-S: Research methodology formulation and follow-up of laboratory experiments, editing of the manuscript.

\section{References}

1- HARTWIG A.: Benzoic acid and alkali benzoates [MAK Value Documentation, 2017]. In: The MAK-Collection for Occupational Health and Safety [Internet]. American Cancer Society; [cited 2020 Jan. 2]. p. 1758-828. Available from: https://onlinelibrary.wiley.com/doi/abs/ 10.1002/3527600418.mb6585e6318, 2018.

2- LENNERZ B., VAFAI S.B., DELANEY N.F., CLISH C.B., DEIK A.A., PIERCE K.A., et al.: Effects of sodium benzoate, a widely used food preservative, on glucose homeostasis and metabolic profiles in humans. Mol Genet Metab [Internet]. 2015 Jan [cited Dec. 26], 114 (1): 739. Available from: https://www.ncbi.nlm.nih.gov/ pmc/articles/PMC4289147/, 2019.

3- SAATCI C., ERDEM Y., BAYRAMOV R., AKAL1N H., TASCIOGLU N. and OZKUL Y.: Effect of sodium benzoate on DNA breakage, micronucleus formation and mitotic index in peripheral blood of pregnant rats and their newborns. Biotechnol Biotechnol Equip [Internet]. 2016 Nov 1 [cited Dec. 26], 30 (6): 1179-83. Available from: https://doi.org/10.1080/13102818.2016.1224979, 2019.

4- KHOSHNOUD M., SIAVASHPOUR A., BAKHSHIZADEH M. and RASHEDINIA M.: Effects of sodium benzoate, a commonly used food preservative, on learning, memory, and oxidative stress in brain of mice. J. Biochem. Mol. Toxicol., Dec. 15; 32, 2017.

5- NOORAFSHAN ALI, MAHBOOBEH ERFANIZADEH and SAIED KARBALAY-DOUST: (PDF) Sodium benzoate, a food preservative, induces anxiety and motor impairment in rats [Internet]. Neurosciences, 19 (1): 248. 2014 [cited Dec. 26]. Available from: https:// . www.researchgate.net/publication/259720636 Sodium _benzoate_a_food_preservative_induces_anxiety _and_motor_impairment_in_rats, 2019.

6- NOORAFSHAN A., ERFANIZADEH M. and KARBALAY-DOUST S.: Stereological studies of the effects of sodium benzoate or ascorbic acid on rats cerebellum. Saudi Med. J. Dec., 35 (12): 1494-500, 2014.

7- RADU-RUSU C.G. and POP M.I.: Study on the Usage of Sodium Benzoate (E 211) in Two Food Categories. Sci. Pap., 68: 6, 2017.

8- JENSEN T., ABDELMALEK M.F., SULLIVAN S., NADEAU K.J., GREEN M., RONCAL C., et al.: Fructose and Sugar: A Major Mediator of Nonalcoholic Fatty Liver Disease. J. Hepatol. [Internet]. 2018 May [cited Dec. 
26];68 (5): 1063-75. Available from: https://www.ncbi. . nlm.nih.gov/pmc/articles/PMC5893377/. 2019.

9- VILLEGAS L.R., RIVARD C.J., HUNTER B., YOU Z., RONCAL C., JOY M.S., et al.: Effects of fructosecontaining sweeteners on fructose intestinal, hepatic, and oral bioavailability in dual-catheterized rats. PLOS ONE [Internet]. 2018 Aug 11 [cited Dec. 26]; 13 (11): e0207024 Available from: https://journals.plos.org/plosone/article? id=10.1371/journal.pone.0207024, 2019.

10- STANHOPE K.L., SCHWARZ J-M. and HAVEL P.J.: Adverse metabolic effects of dietary fructose: Results from recent epidemiological, clinical, and mechanistic studies. Curr. Opin. Lipidol. Jun., 24 (3): 198-206, 2013.

11-YRACHETA J.M., ALFONSO J., LANASPA M.A., RONCAL-JIMENEZ C., JOHNSON S.B., SÁNCHEZLOZADA L.G., et al.: Hispanic Americans living in the United States and their risk for obesity, diabetes and kidney disease: Genetic and environmental considerations. Postgrad Med. Sep., 3; 127 (5): 503-10, 2015.

12- PIPER P.W.: Potential Safety Issues Surrounding the Use of Benzoate Preservatives. Beverages. Jun., 4 (2): 33, 2018.

13- BARROS C.M.M.R., LESSA R.Q., GRECHI M.P., MOUÇO T.L.M., SOUZA M. DAS G.C., WIERNSPERGER N., et al.: Substitution of drinking water by fructose solution induces hyperinsulinemia and hyperglycemia in hamsters. Clin Sao Paulo Braz. Jun., 62 (3): 327-34, 2007.

14- SEMCHYSHYN H.M.: Fructation In Vivo: Detrimental and Protective Effects of Fructose [Internet]. Vol. 2013, BioMed Research International. Hindawi; 2013 [cited Jan 1]. p. e343914. Available from: https://www.hindawi.com/ journals/bmri/2013/343914/, 2021

15- DEKKER M.J., SU Q., BAKER C., RUTLEDGE A.C. and ADELI K.: Fructose: A highly lipogenic nutrient implicated in insulin resistance, hepatic steatosis, and the metabolic syndrome. Am. J. Physiol. Endocrinol. Metab. Nov., 299 (5): E685-694, 2010.

16- TAPPY L., LE K.A., TRAN C. and PAQUOT N.: Fructose and metabolic diseases: New findings, new questions. Nutr Burbank Los Angel Cty Calif. Dec., 26 (11-12): 1044-9, 2010

17- DELHAYE M., LOUIS H., DEGRAEF C., MOINE O.L., DEVIERE J., GULBIS B., et al.: Relationship between hepatocyte proliferative activity and liver functional reserve in human cirrhosis. Hepatology, 23 (5): 1003-11, 1996.

18- MA S., YANG J., LI J. and SONG J.: The clinical utility of the proliferating cell nuclear antigen expression in patients with hepatocellular carcinoma. Tumour Biol. J. Int. Soc. Onco developmental Biol. Med. Jun., 37 (6): 7405-12, 2016.

19- KHODAEI F., KHOLGHIPOUR H., HOSSEINZADEH M. and RASHEDINIA M.: Effect of sodium benzoate on liver and kidney lipid peroxidation and antioxidant enzymes in mice. J. Rep. Pharm. Sci. May, 1; 8 (2): 217, 2019.

20- OE O.: The hepatotoxic effect of halofantrine in guinea pigs. Indian J. Pharmacol. Sep., 1; 36 (5): 303, 2004.

21- RADWAN E., HUSSEIN H., KK A., AZIZ and BARAKAT A.: The Possible Effects of Sodium Nitrite and Sodium Benzoate as Food Additives on The Liver in Male Rats. J. Adv. Biol. Apr., 1; (13): 2347-6893, 2020.

22- CRESCENZO R., BIANCO F., FALCONE I., COPPOLA P., LIVERINI G. and IOSSA S.: Increased hepatic de novo lipogenesis and mitochondrial efficiency in a model of obesity induced by diets rich in fructose. Eur. J. Nutr. Mar., 52 (2): 537-45, 2013.

\section{تأثير الاستخدام المتزامن لأملاح بنزوات الصوديوم وسكر الفركتوز

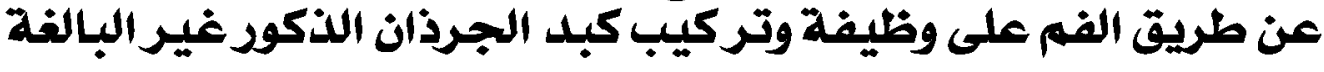

$$
\begin{aligned}
& \text { مقدمة: تستخدم أملاح بنزوات الموديوم بكثرة في حفظ المنتجات والأدوية. يعد سكر الفركتون الموجود بالفواكه والعسل من السكريات }
\end{aligned}
$$

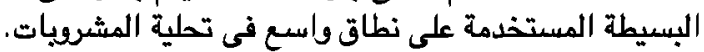

$$
\begin{aligned}
& \text { الهدف من الدراسة: هذه الدراسة تهدف إلى تقييم التآثير المتزامن لاستخدام سكر الفركتوذ وأملاح بنزوات الصوديوم على تركيب ووظيفة }
\end{aligned}
$$

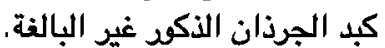

الاستتاج: الاستخدام المتزامن اليومى لفترة طويلة لكل من بنزوات الصوديوم والفركتوز له تأثير ضار على الكبد من الناحية الوظيفية

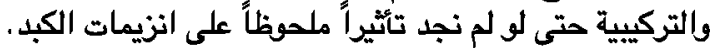

